\title{
KOMPETENSI PENYULUH DALAM MENDUKUNG GERAKAN PEMBERDAYAAN PETANI TERPADU (GPPT) DI KABUPATEN KARANGANYAR
}

\author{
THE COMPETENCE OF EXTENSION AGENTS IN \\ SUPPORTING EMPOWERMENT MOVEMENT OF \\ INTEGRATED FARMERS (EMIF) IN KARANGANYAR \\ REGENCY
}

\author{
Yuliani, Sapja Anantanyu, Agung Wibowo \\ Program Studi Penyuluhan dan Komunikasi Pertanian, Fakultas \\ Pertanian, Universitas Sebelas Maret \\ Jl.Ir.Sutami No.36 A Kentingan Surakarta 57126 Telp./Fax (0271) \\ 637457 \\ Email: Florensia.acun@gmail.com/ Telp. 081214884853
}

\begin{abstract}
This study aims to examine the EmpowermentMovement of Integrated Farmers; the extension agents' competence related with Empowerment Movement of Integrated Farmers; the factors that affecting the competence of extension agents, to examine the effect of factors that affecting the competence of extension agents with extension agents' competence. The location of the study was determined purposively because of the presence of EMIF, where the focus of this movement is the empowerment of farmer groups while there are still many farmer groups that are in the beginner class. The population of this research is the extension agents whose working area is in the same sub district with farmers group on the beginner class. The sampling method was done with total sampling is 32 people. Data analysis using multiple linear regressions. The extension agents' competence in compiling the program is low; The extension agents' competence in preparing the materials, establishing media, agribusiness consulting services, evaluating the implementation of extension, evaluating the impact of extension, conducting the assessment is moderate; The extension agents' competence in the application of the method is high; (3) Factors that affecting the extension agents' competence the ability to mobilizing the group (X1); personality (X2); The attitude of extension agents' (X3); The extension agents'counseling skills (X4); motivation(X6) are moderate; The extension agents' experience (X5) is very low. (4) There is a significant influence between the counseling skills and the motivation with the extension agents' competence and there is no significant influence between the ability to mobilizing the group, personality, attitude of extension agents' and experience with extension agents' competence.
\end{abstract}

Keywords: Competencee, EmpowermentMovement of Integrated Farmers, Extension Agent 


\title{
Yuliani, Anantanyu, Wibowo, Kompetensi, Gerakan,,,
}

\begin{abstract}
Abstrak
Penelitian ini bertujuan untuk mengkaji Gerakan Pemberdayaan Petani Terpadu; kompetensi penyuluh terkait Gerakan pemberdayaan Petani Terpadu; faktor yang mempengaruhi kompetensi penyuluh; pengaruh faktor yang mempengaruhi kompetensi penyuluh dengan kompetensi penyuluh. Lokasi penelitian ditentukan secara sengaja (purposive) karena adanya GPPT yang mana fokus gerakan ini adalah pemberdayaan kelompok tani sedangkan masih banyak terdapat kelompok tani yang berada pada tahapan pemula. Populasi penelitian ini yaitu penyuluh yang wilayah kerjanya di kecamatan dengan elas kelompok tani "pemula". Metode pengambilan sampel dilakukan dengan total sampling yaitu 32 orang. Analisis data menggunakan regresi linier berganda. Hasil penelitian menunjukkan bahwa: (1) Gerakan Pemberdayaan Petani Terpadu dilakukan di Karanganyar untuk mendukung hal ini juga diadakan diklat tematik yang berguna menyiapkan SDM di BP3K. (2) kompetensi penyuluh dalam menyusun programa tergolong rendah; kompetensi penyuluh dalam menyiapkan materi; menetapkan media; jasa konsultasi agribisnis; mengevaluasi pelaksanaan penyuluhan; mengevaluasi dampak penyuluhan; pelaksanaan pengkajian tergolong sedang, kompetensi penyuluh dalam penerapan metode tergolong tinggi, (3) faktor yang mempengaruhi kompetensi, kemampuan menggerakkan kelompok $\left(X_{1}\right)$; kepribadian $\left(X_{2}\right)$; sikap penyuluh $\left(X_{3}\right)$; ketrampilan menyuluh $\left(X_{4}\right)$ dan motivasi $\left(X_{6}\right)$ tergolong sedang tergolong sedang, pengalaman $\left(X_{5}\right)$ tergolong sangat rendah. (4) terdapat pengaruh yang signifikan antara ketrampilan menyuluh dan motivasi dengan kompetensi penyuluh dan terdapat pengaruh yang tidak signifikan antara kemampuan menggerakkan, kepribadian, sikap penyuluh dan pengalaman dengan kompetensi penyuluh.
\end{abstract}

Kata Kunci: Kompetensi, Gerakan Pemberdayaan Petani Terpadu, Penyuluh

\section{PENDAHULUAN}

Pembangunan pertanian sebagai salah satu unsur penggerak dinamika pembangunan Dinamika proses ter-sebut akan terjadi apabila aparatur, petani dan lembaga sosial ekonomi senantiasa berperilaku proaktif. Tak terkecuali penyuluh pertanian, yang mempunyai kedudukan yang strategis sesuai dengan tugasnya sebagai penyelenggara pendidikan non formal bagi petani dan keluarga-nya serta anggota masyarakat lain-nya. Oleh sebab itu, untuk men-jalankan tugas di masa depan penyuluh harus memiliki kualitas sumber daya yang handal. Menurut Mardikanto (1993) Penyuluh yang profesional ialah penyuluh yang mampu merumuskan program-program penyuluhan, memiliki pemahaman yang baik tentang pengertian akan sikap dan peranan organisasi pelayanan penyuluhan di tingkat nasional.

Menurut Slamet (2009) Kompetensi erat kaitannya dengan kemampuan seseorang dalam melakukan suatu pekerjaan. Menjalankan pekerjaan akan maksimal saat 


\section{Jurnal Agritexts Volume 41 Nomer 2 Oktober 2017}

kompetensi yang dimiliki tinggi. Pelatihan merupakan salah satu cara yang banyak dilakukan untuk peningkatan kompetensi dan kinerja penyuluh. Salah satu kegiatan pelatihan bagi peningkatan kompetensi penyuluh ini, terdapat pada Gerakan Pemberdayaan Petani Terpadu (GPTT). Gerakan tersebut mengisyaratkan pentingnya pertanian menuju kemandirian pangan yang kuat dan berkelanjutan sekaligus ramah lingkungan.dengan menyiapkan SDM pertanian. Upaya untuk menyiapkan SDM yang dapat dilakukan yaitu dengan adanya pembinaan bagi penyuluh dan ditindaklanjuti dengan kunjungan kepada kelompok tani secara ter-jadwal. Namun terkait dengan kompetensi penyuluh, saat ini menunjukkan masih lemahnya kompetensi penyuluh pertanian (Anwas 2013).

Kegiatan Pelaksanaan Gerakan Pemberdayaan Petani Terpadu, penyuluh pertanian memiliki peran yang sangat penting terutama dalam me-motivasi, mendampingi dan mengawal petani yang tergabung dalam kelompok tani untuk menerapkan inovasi teknologi. Kondisi di Karanganyar dengan banyak penyuluh yang Sumber Daya Manusianya berada pada posisi jabatan yang cukup tinggi. Hal ini seperti Pelaksana Lanjutan, Penyelian Muda dan Madaya yang cukup mumpuni tetapi masih banyak kecamatan yang kelompok tani berada pada posisi pemula. Hal inilah yang mendorong untuk mengetahui bagaiman pengaruh faktor-faktor yang mempengaruhi kompetensi penyuluh dengan kompetensi penyuluh dalam Gerakan Pemberdayaan Petani Terpadu.

\section{METODE PENELITIAN}

Metode dasar penelitian yang digunakan adalah metode eksplanatori dengan menggunakan teknik survei. Penentuan lokasi penelitian dilakukan secara sengaja (purposive) dengan memilih Kabupaten Karanganyar, dimana ada Gerakan Pemberdayaan Petani Terpadu serta masih banyaknya kelompok tani pemula dengan prosentase penyuluh yang cukup tinggi sebesar $77 \%$. Pengambilan sampel dengan cara sensus atau total sampling, yaitu penyuluh dengan wilayah binaan yang kelas kelompoktaninya "pemula" jumlah responden sebesar 32 responden. Penelitian ini menggunakan data primer dengan menggunakan kuisioner sebagai alatnya dan data sekunder diperoleh dari instansi terkait.

Pengujian kuesioner penelitian dilakukan dengan uji validitas dan reliabilitas. Hasil uji validitas menunjukkan validitas yang tinggi. Hal tersebut dilihat berdasarkan nilai $r_{\text {hitung }}>r_{\text {tabel }}(0,4438)$. Hasil uji reliabilitas juga menunjukkan nilai 
Cronbach alpha adalah 0.993 yang artinya tingkat reliabilitasnya sangat tinggi.

Metode analisis data yang digunakan untuk mengetahui pengaruh faktor- faktor yang mempengaruhi kompetensi dengan kompetensi penyuluh adalah analisis regresi linier berganda, dimana data yang sebelumnya berupa data ordinal ditransformasikan terlebih dahulu menjadi data interval. Untuk menguji analisis regresi dilakukan uji asumsi klasik yaitu uji normalitas dan uji heteroskedastisitas dan uji multikolinearitas. Persamaan analisis regresi yang dipakai dalam penelitian ini adalah sebagai berikut:

$Y=\alpha+b_{1} X_{1}+b_{2} X_{2}+b_{3} X_{3}+$ $b_{4} X_{4} \ldots \ldots . . .+\varepsilon$

Keterangan :

$Y$ : Kompetensi penyuluh

$\mathrm{X}_{1}$ :Kemampuan menggerakkan kelompok

$\mathrm{X}_{2}$ : Kepribadian

$X_{3}$ : Sikap penyuluh

$\mathrm{X}_{4}$ : Ketrampilan menyuluh

$X_{5}$ :Pengalaman dalam pelatihan

$\mathrm{X}_{6}$ :Motivasi

\section{HASIL DAN PEMBAHASAN}

Secara geografis Kabupaten Karanganyar berada diantara koordinat $110^{\circ} 70-110^{\circ} 40^{\prime}$ Bujur Timur dan $70^{\circ} 46^{\prime}-70^{\circ} 28^{\prime}$ Lintang Selatan. Penyuluh yang ada di Karanganyar memiliki jumlah 128 orang. Selain itu untuk jumlah kelompoktani memiliki jumlah kelompok yang masih banyak pada tahapan "pemula" (BP4K Karanganyar). Gerakan Pemberdayaan Petani Terpadu di Kabupaten Karanganyar didukung dengan penyelenggaraan Diklat Tematik yang berguna untuk menyiapkan sumber daya manusia di BP3K. Ini dimaksudkan agar SDM yang ada nantinya mampu menyelenggarakan Diklat Tematik sesuai dengan potensi wilayah. Hal ini juga dilakukan untuk meningkatkan kompetensi dari penyuluh yang terlibat dalam kegiatan Gerakan Pemberdayaan Petani Terpadu. Selain itu, sebagai upaya untuk meningkatkan pemberdayaan petani agar dapat mengubah pola pikir terkait usahatani.

\section{Faktor-faktoryang Mempangaruhi Kompetensi}

Faktor- faktor yang mempengaruhi kompetensi adalah faktorfaktor apa saja yang mempengaruhi kompetensi seseorang meliputi kemampuan menggerakkan kelompok, kepribadian, sikap penyuluh, ketrampilan menyuluh, pengalaman, dan motivasi. 


\section{Jurnal Agritexts Volume 41 Nomer 2 Oktober 2017}

Tabel 1. Distribusi Responden Berdasarkan Faktor-faktor yang Mempengaruhi Kompetensi di Kabupaten Karanganyar

\begin{tabular}{|c|c|c|c|c|c|}
\hline No. & Keterangan & Skor & Kategori & $\begin{array}{l}\text { Jumlah } \\
\text { (Orang) }\end{array}$ & Prosentase (\%) \\
\hline \multirow[t]{6}{*}{1} & Kemampuan & $4-6,77$ & Sangat rendah & 0 & 0 \\
\hline & dalam & $6,78-9,55$ & Rendah & 5 & 15,63 \\
\hline & menggerakkan & $9,56-12,33$ & Sedang & 12 & 37,50 \\
\hline & kelompok & $12,34-15,11$ & Tinggi & 10 & 31,25 \\
\hline & & $15,12-17,89$ & Sangat tinggi & 5 & 15,63 \\
\hline & & Jumlah & & 32 & 100,00 \\
\hline \multirow[t]{6}{*}{2} & Kepribadian & $3-5,19$ & Sangat rendah & 1 & 3,13 \\
\hline & & $5,20-7,39$ & Rendah & 8 & 25,00 \\
\hline & & $7,40-9,59$ & Sedang & 12 & 37,50 \\
\hline & & $9,60-11,79$ & Tinggi & 9 & 28,12 \\
\hline & & $11,80-13,99$ & Sangat tinggi & 2 & 6,25 \\
\hline & & Jumlah & & 32 & 100,00 \\
\hline \multirow[t]{6}{*}{3} & Sikap penyuluh & $3-5,24$ & Sangat rendah & 0 & 0,00 \\
\hline & & $5,25-7,49$ & Rendah & 6 & 18,75 \\
\hline & & $7,50-9,74$ & Sedang & 13 & 40,63 \\
\hline & & $9,75-11,99$ & Tinggi & 11 & 34,37 \\
\hline & & $12-14,24$ & Sangat tinggi & 2 & 6,25 \\
\hline & & Jumlah & & 32 & 100,00 \\
\hline \multirow[t]{6}{*}{4} & Ketrampilan & $12-21,46$ & Sangat rendah & 0 & 0,00 \\
\hline & menyuluh & $51,47-30,92$ & Rendah & 2 & 6,25 \\
\hline & & $30,93-40,39$ & Sedang & 18 & 56,25 \\
\hline & & $40,40-49,86$ & Tinggi & 12 & 37,50 \\
\hline & & 49,87-59,33 & Sangat tinggi & 0 & 0,00 \\
\hline & & Jumlah & & 32 & 100,00 \\
\hline \multirow[t]{6}{*}{5} & Pengalaman & $2-3,18$ & Sangat rendah & 13 & 40,63 \\
\hline & & $3,19-4,37$ & Rendah & 12 & 37,50 \\
\hline & & $4,38-5,56$ & Sedang & 3 & 9,37 \\
\hline & & $5,57-6,75$ & Tinggi & 4 & 12,50 \\
\hline & & $6,76-7,94$ & Sangat tinggi & 0 & 0,00 \\
\hline & & Jumlah & & 32 & 100,00 \\
\hline \multirow[t]{6}{*}{6} & Motivasi & $7-12,64$ & Sangat rendah & 0 & 0,00 \\
\hline & & $12,65-18,29$ & Rendah & 2 & 6,25 \\
\hline & & $18,30-23,94$ & Sedang & 20 & 62,50 \\
\hline & & $23,95-29,59$ & Tinggi & 10 & 31,25 \\
\hline & & $29,60-35,24$ & Sangat tinggi & 0 & 0,00 \\
\hline & & Jumlah & & 32 & 100,00 \\
\hline
\end{tabular}

Sumber: Analisis Data Primer, 2017 
Yuliani, Anantanyu, Wibowo, Kompetensi, Gerakan,,

Kemampuan dalam meng- mampu berdaya sering kali gerakkan kelompoktani tergolong mengalami kendala. Ini karena sedang.Hal ini dikarenkan me- kurang aktif dilakukan.

lakukan kontrol, komunikasi dengan anggota kelompoktani, serta mendorong kelompok tani untuk aktif dalam kegiatan dilakukan penyuluh. Sementara untuk mendorong dalam kerjasama kelompok tani dalam suatu kegiatan kurang sering dilakukan penyuluh.

Kepribadian tergolong kategori yang sedang. Inidikarenakan penyuluh tidak melakukan kegiatan menyelesaikan masalah. Mereka jarang dibantu oleh rekan kerja.

Sikap penyuluh tergolong dalam kategori sedang. Hal ini dikarenakan penyuluh terlibat dalam kegiatan yang dilakukan sasaran. Namun pemantauan ini tidak sering.

Ketrampilan dalam penelitian ini sedang. Ini dikarenakan dalam mempengaruhi kelompok agar

Distribusi pengalaman yang ada kebanyakan tergolong rendah. Ini dikarenakan kebanyakan responden dalam setiap pelatihan berpartisipasi sebagai peserta. Sementara saat jadi peserta cenderung pasif Motivasi disini tergolong sedang. Kejadian dilapang tidak semua menjadikan keberhasilan dalam memberdayakan kelompoktani sebagai suatu kebanggan. Melainkan sebuah tanggung jawab yang sudah semestinya mereka lakukan sebagai seorang penyuluh.

\section{Kompetensi penyuluh}

Kompetensi penyuluh merupakan kemampuan yang harus dimiliki seseorang dalam melakukan suatu pekerjaan dengan tujuan tertentu. Berikut ini penjelasan terkait kompetensi penyuluh: 


\section{Jurnal Agritexts Volume 41 Nomer 2 Oktober 2017}

Tabel 2Distribusi Responden Berdasarkan Kompetensi Penyuluh di Kabupaten Karanganyar

\begin{tabular}{|c|c|c|c|c|c|}
\hline No. & Kompetensi & Skor & Kategori & Jumlah (Orang) & Prosentase (\%) \\
\hline \multirow[t]{6}{*}{1} & Menyusun & $10-17,27$ & Sangat rendah & 1 & 1 \\
\hline & programa & $17,28-24,55$ & Rendah & 18 & 56,25 \\
\hline & penyuluhan & $24,56-31,83$ & Sedang & 11 & 34,37 \\
\hline & pertanian & $31,84-39,11$ & Tinggi & 2 & 6,25 \\
\hline & & $39,12-46,39$ & Sangat tinggi & 0 & 0,00 \\
\hline & & Jumlah & & 32 & 100,00 \\
\hline \multirow[t]{6}{*}{2} & Menyiapkan & $9-15,38$ & Sangat rendah & 0 & 0,00 \\
\hline & materi penyuluhan & $15,39-21,77$ & Rendah & 3 & 9,37 \\
\hline & & $21,78-28,16$ & Sedang & 15 & 46,88 \\
\hline & & $28,17-34,55$ & Tinggi & 10 & 31,25 \\
\hline & & $34,56-40,94$ & Sangat tinggi & 4 & 12,50 \\
\hline & & Jumlah & & 32 & 100,00 \\
\hline \multirow[t]{6}{*}{3} & Jasa konsultasi & $9-16,01$ & Sangat rendah & 0 & 0,00 \\
\hline & agribisnis & $16,02-23,03$ & Rendah & 4 & 12,50 \\
\hline & & $23,04-30,05$ & Sedang & 14 & 43,75 \\
\hline & & $30,06-37,07$ & Tinggi & 12 & 37,50 \\
\hline & & $37,08-44,09$ & Sangat tinggi & 2 & 6,25 \\
\hline & & Jumlah & & 32 & 100,00 \\
\hline \multirow[t]{6}{*}{4} & Menerapkan & $5-8,55$ & Sangat rendah & 0 & 0,00 \\
\hline & metode & $8,56-12,11$ & Rendah & 6 & 18,75 \\
\hline & penyuluhan & $12,12-15,67$ & Sedang & 8 & 25,00 \\
\hline & pertanian & $15,68-19,23$ & Tinggi & 13 & 40,63 \\
\hline & & $19,24-22,79$ & Sangat tinggi & 5 & 15,62 \\
\hline & & Jumlah & & 32 & 100,00 \\
\hline \multirow[t]{6}{*}{5} & Menerapkan & $4-7,27$ & Sangat rendah & 0 & 0,00 \\
\hline & media penyuluhan & $7,28-10,55$ & Rendah & 4 & 12,50 \\
\hline & pertanian & $10,56-13,83$ & Sedang & 16 & 50,00 \\
\hline & & $13,84-17,11$ & Tinggi & 10 & 31,25 \\
\hline & & $17,12-20,39$ & Sangat tinggi & 2 & 6,25 \\
\hline & & Jumlah & & 32 & 100,00 \\
\hline \multirow[t]{6}{*}{6} & Mengevaluasi & $10-18,27$ & Sangat rendah & 0 & 0,00 \\
\hline & pelaksanaan & $18,28-26,55$ & Rendah & 6 & 18,75 \\
\hline & penyuluhan & $26,56-34,83$ & Sedang & 14 & 43,75 \\
\hline & pertanian & $34,84-43,11$ & Tinggi & 12 & 37,50 \\
\hline & & $43,12-51,39$ & Sangat tinggi & 0 & 0 \\
\hline & & Jumlah & & 32 & 100,00 \\
\hline \multirow[t]{6}{*}{7} & Mengevaluasi & $10-17,88$ & Sangat rendah & 1 & 3,13 \\
\hline & dampak & $17,89-25,77$ & Rendah & 3 & 9,38 \\
\hline & penyuluhan & $25,78-33,66$ & Sedang & 14 & 43,75 \\
\hline & pertanian & $33,67-41,55$ & Tinggi & 10 & 31,25 \\
\hline & & $41,56-49,44$ & Sangat tinggi & 4 & 12,50 \\
\hline & & Jumlah & & 32 & 100,00 \\
\hline \multirow[t]{6}{*}{8} & Melaksanakan & $11-19,64$ & Sangat rendah & 0 & 0,00 \\
\hline & pengkajian & $19,65-28,29$ & Rendah & 8 & 25,00 \\
\hline & penyuluhan & $28,30-36,94$ & Sedang & 12 & 37,50 \\
\hline & pertanian & $36,95-45,59$ & Tinggi & 9 & 28,12 \\
\hline & & $45,60-54,24$ & Sangat tinggi & 3 & 9,38 \\
\hline & & Jumlah & & 32 & 100,00 \\
\hline
\end{tabular}

Sumber: Analisis Data Primer, 2017 


\section{Yuliani, Anantanyu, Wibowo, Kompetensi, Gerakan,„,}

Penyusunan programa kebanyakan tergolong rendah. Karena seringkali penyuluh mengerjakannya sendiri dilihat dari data yang dimiliki oleh penyuluhtanpa mengumpulkan kelompoktani untuk diajak berdiskusi.

Kompetensi terkait dengan materi penyuluhan tergolong sedang . Hal ini dikarenakan penyuluh dalam menyampaikan materi kebanyakan belum disesuaikan dengan tema.

Kompetensi jasa konsultasi yang tergolong rendah karena penyuluh tidak melakukan rekomendasi terhadap sasaran. Responden biasanya melakukan hal identifikasi serta analisis usahaterlebih dulu namun analisis usaha sasaran biasanya dilakukan dengan kurang memperhatikan aspek aspek yang ada (aspek sosial,dan teknis).

Kompetensi dalam menerapkan metode penyuluhan pertaniantergolong dalam kategori tinggi ialah metode yang digunakan sesuai dengan apa yang dibutuhkan dan materi yang disampaikan.

Media tergolong dalam kategori sedang karena media yang digunakan disesuaikan dengan materi namun terkadang tanpa melihat sasaran atau tidak melakukan identifikasi sasaran, serta tak ada penjelasan teknis terkait penggunaan media.

Pelaksanan evaluasi penyuluhan pertanian tergolong dalam kategori yang sedang.Pelaksanaan penyuluhan pertanian yaitu merumuskan evaluasi pelaksanaan, menentukan kegiatan yang akan dievaluasi, merekapitulasi sumber dan jenis data sesuai instrumen data dan mentabulasikannya serta menetapkan hasil evaluasi dilakukan oleh penyuluh. Namun yang terkadang dilupakan yaitu dengan tidak menjelaskan sistematika penulisan laporan

Mengevaluasi dampak penyuluhan tergolong sedang. Ini diikarenakan kegiatan yang dilakukan oleh penyuluh yaitu menetapkan tujuan evaluasi dampak, menetapkan metode evaluasi, mengumpulkan data evaluasi melakukan tabulasi. Hal yang tidak dilakukan yaitu menyusun instrumen evaluasi dampak menguji validitas dan reliabilitas dan tidak ada rekomendasi.

Kompetensi pelaksanaan pengkajian penyuluhan pertanian kebanyakan tergolong sedang. Hal ini dikarenakan kegiatan yang dilakukan yaitu menetapkan tujuan pengkajian penyuluhan pertanian, menetapkan metode pengkajian sesuai tujuan, mengumpulkan data pengkajian dan melakukan tabulasi. Hal yang tidak dilakukan yaitu menyusun instrumen pengkajian dan menguji validitas dan reliabilitas dan terkadang lupa untuk menghasilkan rekomendasi. 


\section{Jurnal Agritexts Volume 41 Nomer 2 Oktober 2017}

Analisis Regresi Linier Berganda

Model Persamaan Regresi Faktor yang Mempengaruhi Kompetensi terhadap Kompetensi Penyuluh

$$
\begin{aligned}
& Y=-79,160-0,615 X 1-1,232 \times 2 \\
& +0,638 \times 3+2,786 \times 4+6,621 \times 5 \\
& +7,741 X 6 \\
& \text { Keterangan : } \\
& Y=\text { Kompetensi Penyuluh } \\
& X 1=\text { Kemampuan menggerakkan } \\
& \quad \text { kelompok } \\
& X 2=\text { Kepribadian } \\
& X 3=\text { Sikap penyuluh } \\
& X 4=\text { Ketrampilan menyuluh } \\
& X 5=\text { Pengalaman } \\
& X 6=\text { Motivasi }
\end{aligned}
$$

\section{Uji Koefisien Determinasi}

Koefisien determinasi

digunakan sebagai ukuran untuk menyatakan kecocokan garis regresi yang diperoleh.

Tabel 3.Hasil Uji Model Summary

Nilai Adjusted R Square

\begin{tabular}{lllll}
\hline Model & $\mathrm{R}$ & $\mathrm{R}$ & $\begin{array}{l}\text { Adjusted } \\
\text { Square }\end{array}$ & $\begin{array}{l}\text { Std.Error } \\
\text { of the } \\
\text { Estimate }\end{array}$ \\
1 &, 792 &, 627 &, 537 & 24,22413 \\
\hline \hline
\end{tabular}

Sumber : Analisis Data Primer 2017

Tabel 3 menunjukkan nilai Adjusted R Square adalah 0,537. Hal ini berarti bahwa variabel independen (kemampuan dalam menggerakkan kelompok, kepribadian, sikap penyuluh, ketrampilan menyuluh, pengalaman dalam pelatihan dan motivasi) dapat menjelaskan variabel dependen (kompetensi penyuluh) sebesar $53,70 \%$, sedangkan sisanya $(46,30 \%)$ diterangkan oleh faktor lain yang tidak diteliti seperti keyakinan dan nilai-nilai, isu emosional, kemampuan intelektual, budaya organisasi.

\section{Uji Koefisien Regresi Secara Seren- tak (Uji F)}

Uji $F$ atau uji koefisien regresi secara serentak, digunakan untuk mengetahui pengaruh variabel independen secara serentak terhadap variabel dependen, apakah pengaruhnya signifikan atau tidak.

Tabel 4Hasil Uji Simultan (Uji F) terhadap Variabel Y (Kompetensi penyuluh)

\begin{tabular}{cc}
\hline $\mathrm{F}$ & Sig. \\
\hline 6,996 &, $000^{b}$ \\
\hline
\end{tabular}

Sumber : Analisis Data Primer Tahun 2017

Berdasarkan tabel 5, hasil nilai F hitung sebesar 6,996 dengan nilai probabilitas ( $p$ value) sebesar 0,000 dan tingkat kepercayaan $90 \%(\alpha=$ $0,10)$. Jadi, $p$ value $\leq \alpha$ atau $0,000 \leq$ 0,10 . Berdasarkan perbandingan tersebut maka $\mathrm{HO}$ ditolak dan $\mathrm{H} 1$ diterima, yang berarti variabel independen kemampuan dalam menggerakkan (X1), kepribadian (X2), sikap penyuluh (X3), ketrampilan menyuluh $(X 4)$, pengalaman dalam pelatihan $(X 5)$ serta motivasi 


\section{Yuliani, Anantanyu, Wibowo, Kompetensi, Gerakan,„,}

(X6) mempunyai pengaruh yang signifikan secara bersama-sama terhadap variabel dependen kompetensi penyuluh $(\mathrm{Y})$.

\section{Uji Parsial (Uji t)}

Uji t digunakan untuk menguji pengaruh variabel kemampuan dalam menggerakkan $\left(X_{1}\right)$, kepribadian $\left(X_{2}\right)$, sikap penyuluh $\left(X_{3}\right)$, ketrampilan menyuluh $\left(X_{4}\right)$, pengalaman dalam pelatihan $\left(X_{5}\right)$ dan motivasi $\left(X_{6}\right)$ terhadap variabel dependen kompetensi penyuluh $(\mathrm{Y})$ secara individu.

Tabel 5Hasil Uji Parsial (Uji t) terhadap Variabel Y (Kompetensi Penyuluh)

\begin{tabular}{lccc}
\hline \hline Var & B & Sig & Keterangan \\
\hline (Constant) & $-79,160$ &, 105 & \\
KEMAMPUANMENGGERAKKAN &,- 615 &, 793 & Tidak signifikan \\
KEPRIBADIAN & $-1,232$ &, 671 & Tidak signifikan \\
1 SIKAP PENYULUH &, 638 &, 843 & Tidak signifikan \\
KETRAMPILANMENYULUH & 2,786 &, 037 & Signifikan \\
PENGALAMAN & 6,621 &, 137 & Tidak Signifikan \\
MOTIVASI & 7,741 &, 001 & Signifikan \\
\hline \hline
\end{tabular}

Sumber : Analisis Data Primer Tahun 2017

Pengaruh kemampuan me-nggerakkan kelompok (X1) terhadap kompetensi penyuluh.

Kemampuan menggerakkan kelompok secara parsial tidak mempunyai pengaruh yang signifikan terhadap kompetensi penyuluh dengan tingkat kepercayaan $90 \%$. Adanya perubahan pada kemampuan menggerakkan kelompok tidak menyebabkan perubahan pada kompetensi penyuluh. Maas (2004) dalam penelitiannya menyatakan jika suasana kelompok tidak mendukung kegitan akan susah untuk menggerakkan kelompok. Pengaruh yang tidak signifikan antara kemampuan dalam menggerakkan terhadap kompetensi penyuluh terjadi dikarenakan kemampuan penyuluh dalam menggerakkan kelompok tani dilakukan dengan tidak berkala Pengaruh kepribadian (X2) terhadap kompetensi penyuluh.

Kepribadian secara parsial tidak mempunyai pengaruh yang signifikan terhadap kompetensi penyuluh dengan tingkat kepercayaan $90 \%$. Ada-nya perubahan pada kepribadian tidak menyebab-kan perubahan pada kompetensi penyuluh. Anwar (2016) menyatakan saat ber-konflik dan menyelesaikan konflik juga dipengaruhi oleh kepribadian. Kepribadian tidak bisa menjadi patokan untuk pe-ningkatakan kompetensi karena kepribadian kebanyakan bawaan dari orang tersebut, yang mana kejadian dilapang orang 


\section{Jurnal Agritexts Volume 41 Nomer 2 Oktober 2017}

enggan meminta bantuan kepada rekan kerjanya.

Pengaruh sikap penyuluh (X3) terhadap kompetensi penyuluh.

Sikap penyuluh secara parsial tidak mempunyai pengaruh yang signifikan terhadap kompetensi penyuluh dengan tingkat kepercayaan $90 \%$. Adanya perubahan pada sikap penyuluh tidak menyebabkan perubahan pada kompetensi penyuluh. Eman et al, 2017 menyatakan sikap penyuluh dalam melaku-kan pengawalan dilakukan sebagai suatu kegiatan pendampingan kelompok. Namun yang terjadi di lapang pemantauan tidak dilakukan secara berkala oleh penyuluh yang menyebabkan hasil dari analisis tidak signifikan.

Pengaruh ketrampilan menyuluh (X4) terhadap Kompetensi penyuluh.

Ketrampilan menyuluh secara parsial mempunyai pengaruh yang signifikan terhadap kompetensi penyuluh dengan tingkat kepercayaan $90 \%$. Hasil penelitian Sudana (2016) menyatakan bahwa ketrampilan seseorang dalam melakukan pekerjaan akan berpengaruh pada kompetensi. Ketrampilan penyuluh dalam memberikan tanggapan, memahami informasi yang ada, serta memberikan pengarahan dilakukan oleh penyuluh sehingga dapat dikatakan penyuluh terampil dan mem-pengaruhi kompetensi yang mereka miliki.
Pengaruh Pengalaman (X5) terhadap kompetensi penyuluh

Pengalaman secara parsial tidak mempunyai pengaruh yang signifikan terhadap kompetensi penyuluh dengan tingkat kepercayaan $90 \%$. Adanya perubahan pada pe-ngalaman tidak menyebabkan perubahan pada kompetensi penyuluh. Hasil penelitian Mulyawan (2006) Pengalaman dalam pelatihan memiliki peranan yang penting dalam peningkatan kompetensi. Hal ini berbeda dengan yang terjadi di lapang dari hasil analisis pengalaman menunjukkan pengaruh yang tidak signifikan terhadap kompetensi penyuluh. yang hanya menjadi peserta dan bersikap pasif saat pelatihan dan akan menambah pengetahuan saja.

Pengaruh motivasi (X6) terhadap Kompetensi Penyuluh.

Motivasi secara parsial mempunyai pengaruh yang signifkan terhadap kompetensi penyuluh. Semakin tinggi motivasi diikuti dengan kompetensi penyuluh. Hasil penelitian Satria (2013) menununjukkan peningkatan motivasi maka akan diikuti peningkatan kompetensi. Motivasi berpengaruh dengan kompetensi penyuluh yaitu keinginan penyuluh untuk berhasil memberdayakan kelompok tani sehingga diakui oleh masyarakat bahwa ia telah berhasil. 


\section{Yuliani, Anantanyu, Wibowo, Kompetensi, Gerakan,„,}

KESIMPULAN DAN SARAN

\section{Kesimpulan}

Berdasarkan hasil analisis tentang kompetensi penyuluh dalam mendukung Gerakan Pemberdayan Petani disimpulkan bahwa: Kompetensi penyuluh dalam mendukung Gerakan Pember-dayaan Petani Terpadu dalam menyusun programa penyuluh-an pertanian tergolong dalam kategori rendah; kompetensi dalam menyiapkan materi penyuluhan, kompetensi dalam melaksanakan jasa konsultasi agribisnis, kompetensi dalam menerapkan media penyuluh-an, kompetensi dalam meng-evaluasi pelaksanaan penyuluhan, kompetensi dalam mengevaluasi dampak pe-nyuluhan, kompetensi dalam me-laksanakan pengkajian pe-nyuluhan, tergolong sedang; kompetensi dalam menerapkan metode penyuluhan tergolong tinggi.

Kemampuan menggerakkan kelompok, kepribadian, sikap penyuluh, ketrampilan me-nyuluh dan motivasi tergolong sedang; pengalaman tergolong sangat rendah. Pengaruh faktor yang mempengaruhi kompetensi dengan kompetensi penyuluh dalam mendukung Gerakan Pem-berdayaan Petani Terpadu di Kabupaten Karanganyar adalah sebagai berikut: (a) kemampuan menggerakkan kelompok, kepribadian, sikap penyuluh, ketrampilan menyuluh, peng-alaman dan motivasi secara bersamasama mempunyai pe-ngaruh yang signifikan terhadap kompetensi penyuluh; (b) ketrampilan menyuluh, dan motivasi secara parsial me-mpunyai pengaruh yang signifikan sedangkan (c) kemampuan me-nggerakkan kelompok, kepribadian, sikap penyuluh dan pengalaman tidak mempunyai pengaruh yang signifikan terhadap kompetensi penyuluh.

\section{Saran}

Berdasarkan penelitian yang telah dilakukan, maka saran yang dapat diberikan: Kompetensi dalam me-nyiapkan materi tergolong sedang sehingga perlu ditingkatkan dengan materi yang disampaikan harus disesuaikan dengan tematik (pendampingan RDKK, jajar legowo, pengendalian OPT, kalender tanam, teknis budidaya pertanian) yang ada dalam GPPT; kompetensi dalam jasa konsultasi agribisnis tergolong sedang sehingga perlu ditingkankan dengan lebih memperhatikan aspek sosiologis dan teknis bukan saja aspek ekonomis untuk menambah keuntungan; kompetensi dalam menerapkan media penyuluhan juga perlu ditingkatkan dengan lebih memperhatikan kondisi sasaran, seperti pengunaan pamflet lebih diperbanyak karena akan mempermudah dalam me-nyampaikan materi; kompetensi dalam mengevaluasi pelaksanaan penyuluhan; mengevaluasi dampak serta mengkaji 


\section{Jurnal Agritexts Volume 41 Nomer 2 Oktober 2017}

penyuluhan pertanian tergolong sedang perlu ditingkatkan terutama dalam hal menghasilkan rekomendasi kebanyakan penyuluh berhenti pada tahapan menghasilkan kesimpulan tanpa ada rekomendasi sehingga kedepannya akan lebih baik jika dihasilkan rekomendasinya pula.

Kompetensi penyusunan programa masih rendah karena kurangnya keterlibatan kelompok dalam penyusunan programa, untuk itu kelompoktani harus lebih dirangkul untuk mampu bersamasama melakukan analisis kebutuhan terhadap apa yang mereka butuhkan sehingga GPPT juga bisa terealisasi dengan baik karena kelompok lebih berdaya.

Ketrampilan menyuluh masih perlu ditingkatkan kembali dalam memberikan tanggapan serta memberi pengarahan perlu dilatih, dengan cara lebih mendekatkan diri dengan kelompok agar kelompok mau lebih terbuka pada penyuluh dan penyuluh mampu menanggapi masalah yang ada.

Motivasi sebaiknya ditingkatkan agar kelompoktani lebih berdaya dengan meningkatkan kesadaran penyuluh akan pekerjaan yang dijalani sehingga saat ia berhasil memberdayakan kelompok akan muncul rasa bangga.
DAFTAR PUSTAKA

Anwas, Oos M. 2013. Pengaruh Pendidikan Formal, Pelatihan, Dan Intensitas Pertemuan Terhadap Kompetensi Penyuluh Pertanian. Jurnal Pendidikan dan Kebudayaan 9 (1): 52.

Eman, Juwita Janeke; Jenny Baroleh; Agnes E. Lobo. 2017. Peran Pendamping Terhadap Pemberdayaan Kelompok tani Kakao di Kabupaten Bolaang Mangondow Utara. Jurnal Agri-Sosio-Ekonomi Unsrat. 13(2): 3.

Maas T. Linda. 2004. Peranan Dinamika Kelompok dalam meningkatkan Efektivitas Kerja Tim. Fakulltas Kesehatan Masyarakat Universitas Sumatera Utara.

Mardikanto, Totok. 1993. Penyuluhan Pembangunan Pertanian. Surakarta: UNS Press.

Mulyawan, Budi. 2006. Pengaruh Pengalaman dan Pelatihan Terhadap Peningkatan Kompetensi Profesional Guru.

Satria Okky, Asep kuswara 2013. Pengaruh Motivasi dan Pelatihan Terhadap Kompetensi Kerja serta Implikasinya Pada Produktivitas pegawai Dinas Perhubungan Kota Bandung. Jurnal Ekonomi, Bisnis dan Enterprenuership. 7(2): 75. 
Yuliani, Anantanyu, Wibowo, Kompetensi, Gerakan,,

Slamet, Margono. 2009. Perkembangan Penyuluhan Teori dan Praktek. Bogor: Program Mayor Penyuluhan Pembangunan Departemen Komunikasi \& Pengembangan Masyarakat Fakultas Ekologi Manusia, IPB.
Sudana 2016. Pengaruh Pendidikan dan Pelatihan Terhadap Kompetensi Serta Dampaknya Pada Kinerja Pramuwisata Bali. Jurnal IPTA 4(2): 55.

Wibowo. 2007. Manajemen Kinerja. Jakarta: PT Raja Grafindo Persada. 